\title{
ANÁLISE DA EFICIÊNCIA DE FILME BIODEGRADÁVEL INCORPORADO DE CHÁ VERDE PARA O AUMENTO DA VIDA ÚTIL DE TOMATES
}

\author{
G. M. SPOHR ${ }^{1}$, L. C. MOHR ${ }^{1}$, C. S. de QUADROS ${ }^{1}$, R. Z. TERNUS ${ }^{1}$, S. MENONCIN $^{1}$ e \\ F. DALCANTON'1. \\ ${ }^{1}$ Universidade Comunitária da Região de Chapecó, Área de Ciências Exatas e \\ Ambientais. \\ E-mail para contato: gabispohr@unochapeco.edu.br
}

RESUMO - O Brasil é o quinto maior produtor de tomates no mundo, porém após a colheita este deteriora rapidamente. Uma técnica atualmente pesquisada para a extensão da vida útil de frutos são os recobrimentos biodegradáveis. Pensando nisso, este trabalho teve como objetivo utilizar filmes biodegradáveis incorporados de chá verde para recobrir tomates. Para a avaliação da eficiência do recobrimento utilizaram-se filmes com 5\% de fécula de mandioca, fécula acrescida de chá verde (1:1) e os tomates sem recobrimento (controle). Realizaram-se análises físicoquímicas, e como resultado não foi observada diferença significativa entre os tratamentos até aproximadamente 20 dias, porém os frutos recobertos somente com a fécula obtiveram 15 dias a mais de vida útil. Com isso, conclui-se que o chá verde apesar de possuir capacidade bactericida e antioxidante não foi eficiente para estender a vida útil do tomate nas condições estudadas, porém o recobrimento somente com a fécula de mandioca mostrou-se uma técnica viável.

\section{INTRODUÇÃO}

O tomate apresenta-se entre os frutos mais comercializados no mundo, e o Brasil é o quinto maior produtor mundial, entretanto grande parte desta produção sofre danos que dificultam a sua comercialização, consequência de técnicas inadequadas em todas as etapas da colheita até os supermercados (MELO, 2012; PANOZZO, 2013). Perdas significativas são verificadas na pós-colheita, ocasionadas por injurias mecânicas, armazenamento e transporte inadequado, e ampla exposição no varejo, sendo porta de entrada para a contaminação por fungos e bactérias (CHITARRA \& CHITARRA, 2005).

Uma alternativa que está sendo bastante estudada para aumentar o período de armazenamento de frutas, afim de manter a qualidade e estender a vida útil destes produtos é o desenvolvimento de recobrimentos biodegradáveis (DONHOWE E FENNEMA,1994). Os recobrimentos biodegradáveis caracterizam-se por apresentarem bom aspecto, não são pegajosos, são brilhantes e transparentes, melhorando o aspecto visual dos frutos, e não sendo tóxicos, podem ser ingeridos juntamente com o produto protegido. Segundo BOBBIO e BOBBIO (1984) o uso de películas (filmes) comestíveis é uma proposta que pode ser usada com a mesma finalidade da cera. Nesta técnica, utilizam-se como matéria-prima polissacarídeos, proteínas ou 


\section{9 a 22 de outubro de 2014 \\ Florianópolis/SC}

lipídeos. Estas matérias primas de base para a formação do filme apresentam-se, em geral, como um produto comercial de baixo custo (LEMOS, 2006; NELSON; FENNEMA, 1991). No momento da preparação do filme deve-se buscar formulações que minimizem a perda de matéria fresca sem restringir excessivamente as trocas gasosas (CERQUEIRA, 2007).

Os recobrimentos alimentícios podem melhorar o marketing alimentício, com relação a qualidade nutricional, segurança e aumento no tempo de conservação, pois tem muitas funções, entre elas, retardar as perdas de umidade, retardar as trocas gasosas, aumentar a integridade estrutural, promovendo alguma proteção física contra injúrias, reter componentes voláteis, constituintes do odor e do sabor, ou mesmo conter aditivos alimentícios, como agentes antimicrobianos (DONHOWE; FENNEMA, 1994; KROCHTA; DE MULDER-JOHNSTON, 1997; NELSON; FENNEMA, 1991; KESTER; FENNEMA,1986).

As substâncias que possuem atividade antimicrobiana e antioxidante são incorporadas aos filmes, a fim de auxiliar na manutenção da vida útil dos frutos. Por isso estuda-se a incorporação de compostos, como por exemplo, chá verde, óleos essenciais de cravo e canela, entre outras substâncias aos filmes biodegradáveis. As propriedades do chá verde têm sido amplamente estudadas, pois as catequinas presentes no chá demonstram atividades: antioxidante, antiinflamatória, quimioprotetora, anticarcinogênica e antimicrobiana (SCHMITZ, 2005).

Pensando nisto, este trabalho teve como objetivo analisar a eficiência do uso de filmes biodegradáveis incorporados de chá verde para o aumento da vida útil de tomates, através de análises físico-químicas.

\section{METODOLOGIA}

Os tomates tipo Carmen foram adquiridos em uma distribuidora local (Chapecó - SC) e selecionados em relação ao tamanho semelhante, e ao ponto de maturação "pintado", como são chamados os frutos que possuem no mínimo $70 \%$ de sua coloração verde (BRASIL, 1995). A fécula de mandioca (marca Sevanhani) foi usada como recobrimento biodegradável.

Os frutos foram higienizados com água corrente e detergente neutro, após ficaram imersos em uma solução de 2-2,5 \% de hipoclorito de sódio por cerca de 20 minutos. Todos os experimentos deste trabalho foram realizados nos laboratórios de Bromatologia e Operações Unitárias I e II da Unochapecó.

Os tratamentos realizados foram: frutos recobertos com $5 \%$ de fécula de mandioca, com fécula incorporada com chá verde (Marca Yamamotoyama) (1:1) e sem recobrimento (controle). A formação da cobertura feita apenas com fécula de mandioca, ocorreu a partir da gelatinização da mesma, obtida da seguinte forma: primeiramente pesou-se em balança analítica (B-TEC 3100, Tecnal, Piracicaba, Brasil) a quantidade da fécula e adicionou-se água destilada, a fim de obter a concentração de $5 \%$. A solução, feita em béqueres, foi aquecida e agitada constantemente de forma manual até atingir a temperatura de $76^{\circ} \mathrm{C}$, temperatura esta necessária para a gelatinização da fécula. Após, resfriou-se a temperatura ambiente, para que os frutos fossem mergulhados neste 


\section{9 a 22 de outubro de 2014 \\ Florianópolis/SC}

filme sem causar alterações pelo calor. Os frutos ficaram imersos no filme, durante 30 segundos.

Para o filme acrescido do chá verde, primeiramente, foi realizado o preparo do chá. Pesou-se $50 \mathrm{~g}$ de chá verde e dilui-se em $1000 \mathrm{~mL}$ de água, aqueceu-se em chapa de aquecimento por 30 minutos à $80^{\circ} \mathrm{C}$, então, essa mistura foi coada, e o volume de líquido foi medido. Adicionou-se então a mesma quantidade de água destilada, e calculou-se para esta quantidade de líquido, $5 \%$ de fécula, ficando assim um filme com $50 / 50 \mathrm{v} / \mathrm{v}$ de chá e água. Misturou-se a fécula, ao chá e à água e levou-se novamente ao aquecimento, até atingir a temperatura de $76{ }^{\circ} \mathrm{C}$. Após a gelatinização, esperou-se esfriar até a temperatura ambiente, e os frutos foram submersos por 30 segundos.

Após a retirada dos frutos submersos no filme, os mesmos foram colocados em grades plásticas expostas à temperatura ambiente para a secagem. Após 24 horas os frutos foram retirados das grades e colocados em bancadas laboratoriais. As análises físico-químicas foram realizadas duas vezes por semana, sendo que o tempo total de análises se deu até o final da vida útil dos tomates (impróprio para o consumo). A temperatura e a umidade ambiente foram acompanhadas durante todo o tempo de experimento, com aparelho medidor de temperatura e umidade (0609, Incoterm, China).

A análise de sólidos totais foi realizada com o auxílio de um refratômetro portátil (Q7674, Quimis, Diadema, Brasil), que era calibrado a cada análise com água destilada. O pH dos frutos foi medido com um pHmetro (Q405M, Quimis, Diadema, Brasil), calibrado no início de cada análise com as soluções padrão. A análise de acidez titulável foi realizada segundo a metodologia do Instituto Adolfo Lutz (2011) com solução padrão de $\mathrm{NaOH}$ (Vetec) 0,01 M.

A perda de massa foi acompanhada com pesagens em balança analítica, sendo uma análise não destrutiva. A análise de cor e aspecto visual foi feita com fotos tiradas com máquina digital (DSC-W310, Sony, China) de 12.6 megapixels, dentro de uma caixa completamente branca, com luzes posicionadas de forma a não dar reflexo e nem alterar a cor dos frutos. Os frutos foram posicionados sempre do mesmo modo dentro da caixa.

Todas as análises foram realizadas em triplicata. Os resultados foram analisados estatisticamente utilizando o software Statistica 7.0 (StatSoft ${ }^{\circledR}$ ) através da análise de variância (ANOVA) pelo teste de Tukey, com $5 \%$ de probabilidade, ou seja, diferenças significativas apresentam $\mathrm{p} \leq 0,05$.

\section{RESULTADOS E DISCUSSÃO}

O tempo total dos experimentos, ou seja, final da vida útil para os diferentes tratamentos foram diferentes, sendo que para os frutos recobertos com $5 \%$ de fécula o total de dias analisados foi de 35 dias, 22 dias para os frutos controle e 19 dias para os frutos com o filme incorporado de chá verde. Por isto, os dados que serão expostos a seguir terão diferentes durações. 
Como as análises de $\mathrm{pH}$ foram feitas em triplicata de amostra, os resultados estão representados na Tabela 1 com a média e o desvio padrão. Pode-se verificar ainda que os valores de pH não seguem uma linearidade, pois as amostras são destrutivas e para cada dia foram utilizados 3 tomates diferentes. Como os tratamentos tiveram tempos diferentes de duração, a análise estatística foi realizada até o momento em que se podia comparar os tratamentos, por isto o tratamento do filme incorporado com chá verde até 19 dias não apresentou diferença significativa nos valores de $\mathrm{pH}$ comparado com os tratamentos apenas com a fécula e sem fécula (controle). Como o tratamento controle durou 3 dias a mais, foi novamente realizada a analisa estatística e ficou demonstrado que não há diferença significativa com o fruto recoberto com apenas a fécula de mandioca. Esta forma de análise estatística em diferentes tempos foi realizada também para as análises de sólidos solúveis e acidez titulável.

Tabela 1: Valores médios de $\mathrm{pH}$ para os diferentes tratamentos ao longo do tempo (dias)

\begin{tabular}{cccc}
\hline Dia & Controle & $\mathbf{5 \%}$ & Chá \\
\hline \hline $\mathbf{1}$ & $4,49 \pm 0,34^{\mathrm{a}}$ & $4,13 \pm 0,06^{\mathrm{a}}$ & $4,23 \pm 0,10^{\mathrm{a}}$ \\
$\mathbf{5}$ & $4,4 \pm 0,16^{\mathrm{a}}$ & $4,40 \pm 0,07^{\mathrm{a}}$ & $4,33 \pm 0,05^{\mathrm{a}}$ \\
$\mathbf{8}$ & $4,13 \pm 0,08^{\mathrm{a}}$ & $4,22 \pm 0,05^{\mathrm{a}}$ & $4,32 \pm 0,05^{\mathrm{a}}$ \\
$\mathbf{1 2}$ & $4,26 \pm 0,03^{\mathrm{a}}$ & $4,32 \pm 0,19^{\mathrm{a}}$ & $4,07 \pm 0,02^{\mathrm{a}}$ \\
$\mathbf{1 9}$ & $4,17 \pm 0,09^{\mathrm{a}}$ & $4,21 \pm 0,06^{\mathrm{a}}$ & $4,33 \pm 0,27^{\mathrm{a}}$ \\
$\mathbf{2 2}$ & $4,16 \pm 0,05^{\mathrm{a}}$ & $4,15 \pm 0,05^{\mathrm{a}}$ & - \\
$\mathbf{2 6}$ & - & $4,16 \pm 0,04^{\mathrm{a}}$ & - \\
$\mathbf{2 9}$ & - & $4,21 \pm 0,06^{\mathrm{a}}$ & - \\
$\mathbf{3 5}$ & - & $4,34 \pm 0,17^{\mathrm{a}}$ & - \\
\hline
\end{tabular}

Médias seguidas de mesma letra na coluna não diferem entre si pelo teste de Tukey.

Assim como os valores de $\mathrm{pH}$, as análises de sólidos solúveis (SST) para os diferentes tratamentos não apresentaram diferença significativa nas condições estudadas. Os valores de sólidos solúveis podem ser observados na Tabela 2. Como no presente estudo, a pesquisa realizada por Bolzan (2008) com coberturas a base de fécula de mandioca e éster de sacarose aplicadas em tomates não apresentaram diferenças significativas na análise de sólidos totais.

Tabela 2: Valores médios de SST para os diferentes tratamentos ao longo do tempo (dias)

\begin{tabular}{cccc}
\hline Dia & Controle & $\mathbf{5 \%}$ & Chá \\
\hline \hline $\mathbf{1}$ & $4,53 \pm 0,17^{\text {a }}$ & $4,63 \pm 0,09^{\text {a }}$ & $4,83 \pm 0,12^{\text {a }}$ \\
$\mathbf{5}$ & $4,17 \pm 0,09^{\text {a }}$ & $4,03 \pm 0,12^{\text {a }}$ & $4,13 \pm 0,25^{\text {a }}$ \\
$\mathbf{8}$ & $3,93 \pm 0,05^{\text {a }}$ & $4,83 \pm 0,23^{\text {a }}$ & $3,77 \pm 0,21^{\text {a }}$ \\
$\mathbf{1 2}$ & $4,23 \pm 0,52^{\text {a }}$ & $3,97 \pm 0,12^{\text {a }}$ & $3,57 \pm 0,33^{\text {a }}$ \\
$\mathbf{1 9}$ & $3,33 \pm 0,47^{\text {a }}$ & $4,17 \pm 0,62^{\text {a }}$ & $3,43 \pm 0,33^{\text {a }}$ \\
$\mathbf{2 2}$ & $3,60 \pm 0,14^{\text {a }}$ & $4,00 \pm 0,08^{\text {a }}$ & - \\
$\mathbf{2 6}$ & - & $3,53 \pm 0,37^{\text {a }}$ & - \\
$\mathbf{2 9}$ & - & $3,90 \pm 0,29^{\text {a }}$ & - \\
$\mathbf{3 5}$ & - & $3,97 \pm 0,21^{\text {a }}$ & - \\
\hline
\end{tabular}

Médias seguidas de mesma letra na coluna não diferem entre si pelo teste de Tukey. 
Como era de se esperar, baseando-se nos resultados obtidos para a análise de pH e sólidos solúveis, os valores de acidez titulável (AT) (Tabela 3) não apresentaram diferença significativa entre os tratamentos. Cabe ressaltar que as análises estatísticas foram realizadas para diferentes tempos, pois os frutos recobertos com a fécula incorporada de chá verde e os frutos não recobertos tiveram um menor tempo de vida útil, 19 dias e 22 dias, respectivamente, demonstrando desta forma que os frutos recobertos apenas com a fécula foram mais eficientes, durando 13 dias a mais que o controle e 16 dias a mais do que a fécula com chá verde, totalizando uma vida de útil do tomate de 35 dias.

Tabela 3: Valores médios da AT para os diferentes tratamentos ao longo do tempo (dias)

\begin{tabular}{cccc}
\hline Dia & Controle & $\mathbf{5 \%}$ & Chá \\
\hline \hline $\mathbf{1}$ & $0,04 \pm 0,03^{\mathrm{a}}$ & $0,05 \pm 0,00^{\mathrm{a}}$ & $0,06 \pm 0,01^{\mathrm{a}}$ \\
$\mathbf{5}$ & $0,06 \pm 0,00^{\mathrm{a}}$ & $0,06 \pm 0,00^{\mathrm{a}}$ & $0,07 \pm 0,01^{\mathrm{a}}$ \\
$\mathbf{8}$ & $0,07 \pm 0,06^{\mathrm{a}}$ & $0,06 \pm 0,01^{\mathrm{a}}$ & $0,06 \pm 0,00^{\mathrm{a}}$ \\
$\mathbf{1 2}$ & $0,07 \pm 0,00^{\mathrm{a}}$ & $0,08 \pm 0,00^{\mathrm{a}}$ & $0,06 \pm 0,00^{\mathrm{a}}$ \\
$\mathbf{1 9}$ & $0,07 \pm 0,00^{\mathrm{a}}$ & $0,05 \pm 0,01^{\mathrm{a}}$ & $0,07 \pm 0,01^{\mathrm{a}}$ \\
$\mathbf{2 2}$ & $0,06 \pm 0,00^{\mathrm{a}}$ & $0,06 \pm 0,01^{\mathrm{a}}$ & - \\
$\mathbf{2 6}$ & - & $0,06 \pm 0,01^{\mathrm{a}}$ & - \\
$\mathbf{2 9}$ & - & $0,05 \pm 0,01^{\mathrm{a}}$ & - \\
$\mathbf{3 5}$ & - & $0,07 \pm 0,01^{\mathrm{a}}$ & - \\
\hline
\end{tabular}

Médias seguidas de mesma letra na coluna não diferem entre si pelo teste de Tukey.

Analisando os resultados de perda de massa da Figura 1, percebe-se que os frutos com o tratamento $5 \%$ de fécula, obtiveram a menor perda, ficando com uma média de $8,4 \%$ ao final de 35 dias. Já os frutos com tratamento incorporado com o chá perderam em média 8,8 \%, e os frutos controle obtiveram a maior perda, sendo esta de 8,8\%. Como observado, as perdas de massa foram maiores nos tratamentos controle e com os frutos recobertos com fécula e chá verde. Sendo necessário ainda ressaltar, que estes valores são com 22 e 19 dias de experimento, respectivamente. Comparando, por exemplo, a perda de massa no final da vida útil do tomate com fécula acrescida de chá (19 dias), com os frutos recobertos com apenas a fécula em 19 dias (7\%), a perda no primeiro caso é aproximadamente $2 \%$ a mais.

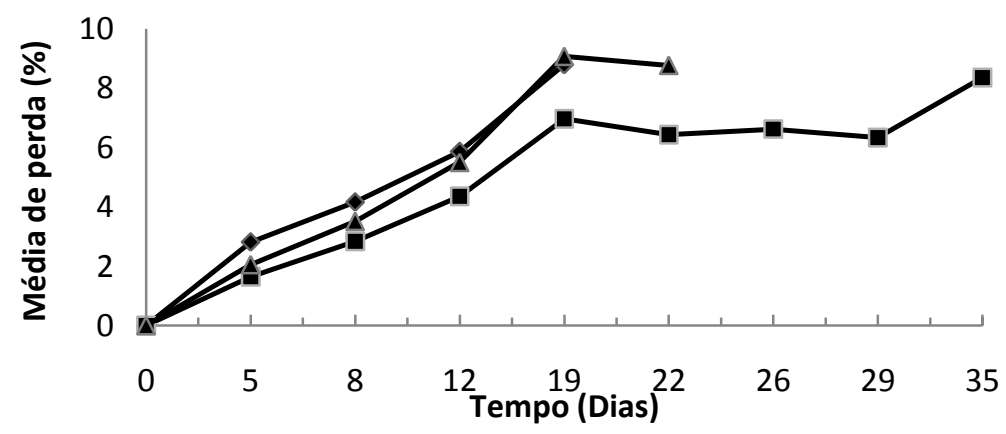

Figura 1. Valores de perda de massa (\%) ao longo da vida de útil do tomate (dias) para os tratamentos: $(\boldsymbol{\square}) 5 \%$ de fécula, $(\diamond)$ fécula acrescida de chá verde e $(\boldsymbol{\Delta})$ controle. 
A perda de massa ocorrida por esses frutos pode ser atribuída à degradação das membranas celulares, que funcionam como barreiras aos movimentos da célula. Durante a senescência do fruto ocorre uma desintegração desta barreira. Portanto, essa modificação da membrana pode ocasionar a perda de peso dos tomates, não só pela perda de água, mas também através da perda de calor do fruto (BOLZAN, 2008). Damasceno et al. (2003), descrevem que os tomates recobertos com fécula de mandioca comparados ao branco, não apresentaram diferença significativa entre eles, mesmo que o tratamento com $3 \%$ tenha sido o que apresentou a menor perda de peso em relação ao branco e ao tratamento $2 \%$. Guedes (2007) aplicando cobertura de fécula de mandioca em mangas, não observou diferença entre os tratamentos e o branco, concluindo que esta cobertura é semi-permeável e possibilita as trocas gasosas com o ambiente, favorecendo a senescência do fruto.

Para a análise da influência da aplicação das coberturas na cor do tomate, foram capturadas as imagens ao longo da durabilidade dos frutos e a análise se deu de maneira visual e comparativa, conforme ilustrado na Figura 2.
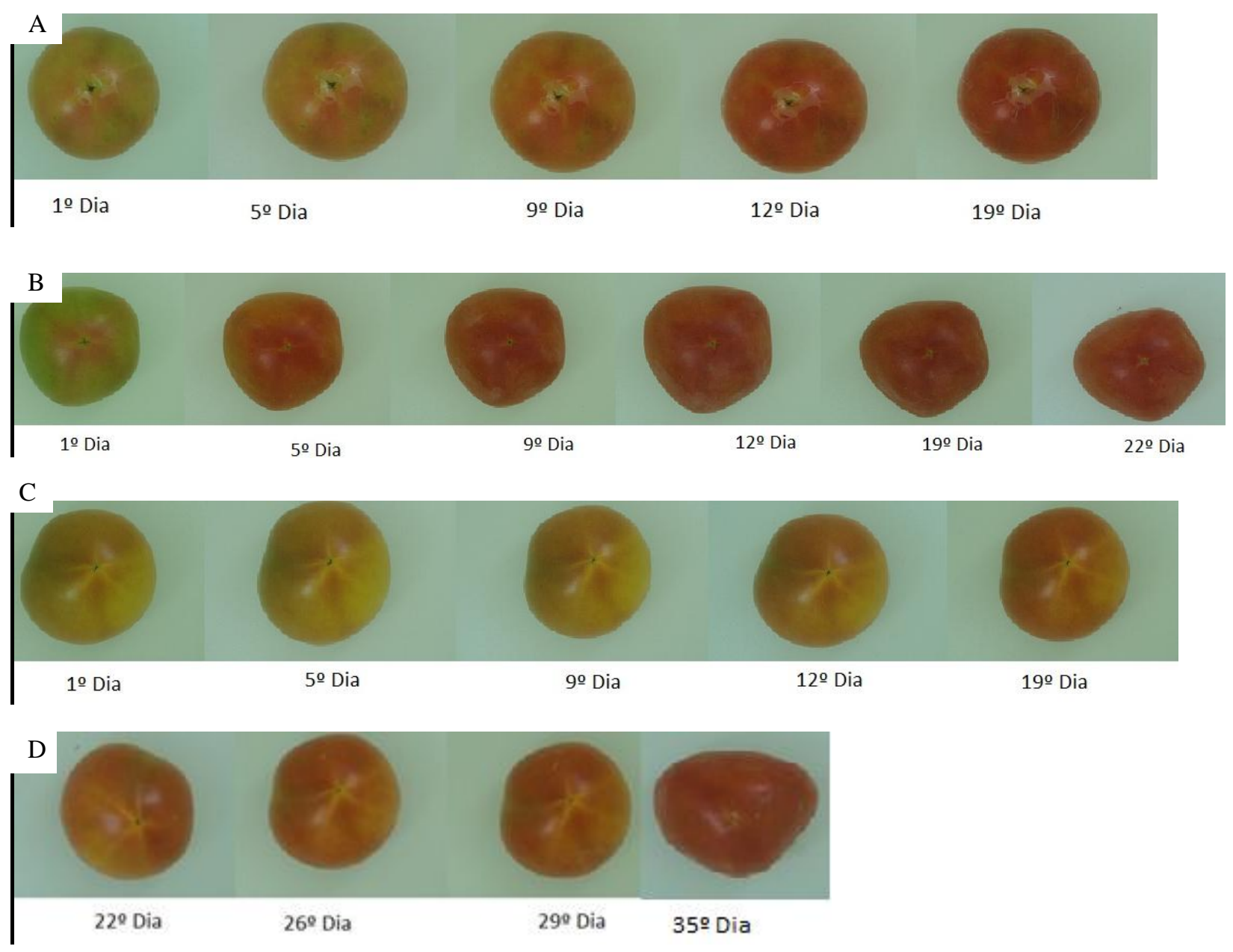

Figura 2: Ganho de cor (maturação) dos frutos ao longo do tempo dias. A: recobertos com fécula acrescida de chá verde. B: controle. C/D: recobertos com fécula $5 \%$. 


\section{9 a 22 de outubro de 2014 \\ Florianópolis/SC}

Como pode-se observar na Figura 2 ao longo do tempo houve um ganho da coloração vermelha dos frutos, representando o amadurecimento dos mesmos, em todos os tratamentos estudados. Na Figura 2B (controle) a coloração vermelha apresentou-se mais rapidamente que nos outros tratamentos, mostrando o amadurecimento natural do fruto. Já na Figura 2A (chá verde + fécula) o amadurecimento foi mais tardio, porém mais intenso que a Figura 2C (apenas fécula).

Juntamente com todas as análises citadas acima, um ponto muito importante que deve ser avaliado é o número de descartes realizados ao longo do tempo. Descartes estes devido a frutos com apodrecimento, murchamento, entre outras características que não os tornam mais aptos para o consumo. Por isto, a Tabela 4 apresenta o número de frutos descartados por apodrecimento ou por murchamento ao longo de 19 dias de experimento.

Tabela 4: Número de frutos descartados até o $19^{\circ}$ dia de experimento

\begin{tabular}{ccc}
\hline Amostra & Apodrecimento & Murchamento \\
\hline \hline Controle & 49 & 1 \\
Chá & 53 & 5 \\
$\mathbf{5 \%}$ & 8 & 2 \\
\hline
\end{tabular}

Como pode ser observado na Tabela 4 a maior parte dos frutos foi descartada por apodrecimento, e os frutos com o tratamento contendo chá, obtiveram o maior descarte. Comparando os frutos controle e tratamento com chá verde, com os frutos que estavam apenas recobertos com $5 \%$ de fécula, percebe-se uma grande diferença na quantidade de frutos descartados. Na condição estudada o acréscimo do chá verde à fécula não se mostrou eficaz contra o desenvolvimento de microrganismos.

\section{CONCLUSÃO}

Apesar das análises de $\mathrm{pH}$, acidez titulável e sólidos totais não apresentarem diferença significativa entre os tratamentos estudados, foi possível observar através da perda de massa, fotos e perdas por apodrecimento que os frutos recobertos com $5 \%$ de fécula de mandioca foram eficazes para a extensão da vida útil do tomate. Esperava-se que o chá verde tendo ação antimicrobiana comprovada, fosse mais eficiente que apenas o recobrimento com fécula, porém isto não foi observado nas condições estudadas no presente trabalho. Recomenda-se a continuação destes estudos, analisando outras concentrações de chá verde, e até mesmo de outras substâncias com poder antimicrobiano.

Portanto, conclui-se que o tratamento com filmes biodegradáveis feitos a partir de fécula de mandioca, na concentração de $5 \%$, é eficiente no aumento de vida útil de tomates. Cabe salientar ainda que esta tecnologia de aplicação de recobrimento de frutos com fécula de mandioca, além de a matéria-prima apresentar baixo custo, a produção não demanda grandes investimentos, sendo possível a sua aplicação em escala industrial. 


\section{REFERÊNCIAS}

BOBBIO, P. A.; BOBBIO, F. O. Material de embalagem. In: Química de processamento de alimentos. Campinas: Fundação Cargill, 1984. Cap. 9, p. 189-202

BOLZAN, R. P. Biofilmes comestíveis para a conservação pós-colheita de tomate 'Dominador'. Curitiba. Dissertação (Mestrado em Ciências) - Universidade Federal do Paraná, 2008.

BRAIN, MARSHALL, Como Funciona a Conservação dos Alimentos; Disponível em: http://lazer.hsw.uol.com.br/conservacao-de-alimentos.htm. Acesso em: 11/04/2014.

BRASIL. Ministério da agricultura, abastecimento e reforma agrária. Portaria $n^{\circ} 553$ de 15 de setembro de 1995. Regulamento Técnico de identidade e Qualidade do tomate. 1995.

CERQUEIRA, T.S. Recobrimentos comestíveis em goiabas cv. 'kumagai'. Piracicaba, SP. Universidade de São Paulo. Dissertação - Escola Superior de Agricultura Luiz de Queiroz. 2007.

CHITARRA, M. I. F; CHITARRA, A. B. Pós colheita de frutos e hortaliças: fisiologia e manuseio. Lavras: Esal/Faepe, 293p, 1990.

DONHOWE, G.; FENNEMA, O. Edible films and coatings:characteristics, formation, definitions, and testing methods. In: KROCHTA, J.M.; BALDWIN, E.A.; NISPEROS. 1994.

CARRIEDO,M.O. (Ed.). Edible coatings and films to improve food quality. Lancaster: Tec. Publ. Co., 1994. p.1-24.

INSTITUTO ADOLFO LUTZ. Métodos físico-químicos para análise de alimentos. Disponível em: $<$ http://www.ial.sp.gov.br/index.php?option=com_remository\&Itemid=7\&func=select\&orderby $=1 \&$ Itemid $=7>$. Acesso em: 18/04/ 2014.

KESTER, J. J; FENNEMA, O.R. Edible films and coatings: A review. Food Tec., Chicago, v.42,47$59,1988$.

LEMOS, ODAIR LACERDA et al; Utilização de Biofilme Comestível na Conservação de Pimentão 'Magali R' . Vitória da Conquista,BA: UESB 2006. Dissertação-Universidade Estadual do Sudoeste da Bahia, 2006.

MELO, P. C. T. Panorama da Agroindústria do Tomate no Mundo. $6^{\circ}$ Congresso brasileiro de tomate industrial. Piracicaba, 2012.

NELSON, K.L; FENNEMA, O.R. Methylcellulose films to prevent lipid migration in confectionary products. Food Sci, Chicago v. 56, n.2, p. 504-509, 1991.

PANOZZO, A. Microstructure and bioaccessibility of different carotenoid species as affected by high pressure homogenisation: A case study on differently coloured tomatoes. Food Chemistry, p.4094-4100, 2013.

SCHMITZ, W.O. Atividades antimicrobianas e quimioprotetoras do extrato etanólico de chá verde (Camellia sinensis). Universidade Estadual de Londrina. Centro de Ciências Biológicas. Programa de Pós-Graduação em Patologia Experimental. Londrina, PR, 2005. 